\title{
DESIGN AND EVALUATION OF A MOOC FOR CLINICAL EDUCATORS
}

\author{
Olivares-Olivares SL ${ }^{1 *}$, Turrubiates-Corolla $\mathrm{ML}^{1}$, Esperón- \\ Hernández $\mathrm{RI}^{2}$ and Sánchez-Mendiola $\mathrm{M}^{3}$ \\ ${ }^{1}$ Tecnologico de Monterrey, Escuela de Medicina y Ciencias de la Salud, Mexico \\ ${ }^{2}$ Universidad Westhill, Facultad de Medicina, Mexico \\ ${ }^{3}$ Universidad Nacional Autónoma de México, Facultad de Medicina, Mexico
}

\begin{abstract}
The MOOCs offer education with high quality standards and have the potential to offer better educational experiences within learning communities where students and teachers from multiple institutions and areas participate. Clinical professors need to be continuously trained with new alternatives that reduce the gap of traditional education with the needs of students. In addition, it is essential to move from education focused exclusively on science, towards a comprehensive education focused on the needs of the most important actor: the patient. The purpose was to design, implement, and evaluate a MOOC on educational evaluation in health sciences. The content of the MOOC was designed and developed with the participation of 15 professors from three universities in Mexico. A pilot was implemented during September-October 2019 to train at least 30 teachers from the three universities. An instrument was designed to measure the fulfillment of teachers' expectations. The pre-test was applied before starting the pilot course and the post-test at the end of the program. The tests were answered by 29 of 57 professors, whose data were analyzed using the t-student statistical test. The course was successfully completed by 33 of 57 teachers. The results of the statistical test show that there is a significant difference. The expectations of the teachers who completed the course were exceeded. For the educational proposal to be considered valuable, it must consistently meet the participant's learning needs according to the effort and cost invested. Knowing the perceived value indicates how participants conceive the value of the program. In this sense, MOOCs represent opportunities for teacher training in educational evaluation. The project has great potential for impact at the Latin American level.
\end{abstract}

Keywords: MOOC, clinical teachers, health sciences, clinical competence, patientcentered learning, educational innovation

\section{Introduction}

Massive Open Online Courses (MOOCs) are offered over the Internet and are open to anyone in the world at low cost. These are an alternative to reduce the cost compared to traditional training and, therefore, increase the participant's value. The MOOCs are intended to expose students to new disciplines, stimulate new interests, learn ideas, and realize a learning community (Engle et al., 2015). The MOOCs offer education with high-quality standards to a massive number of participants around the world who have access to the Internet at a low cost (Aboshady et al., 2015). According to Daniel et al. (2015), these courses have the potential to offer better educational experiences within learning communities where students and teachers from multiple institutions and areas participate. Clinical professors need to be continuously trained with contemporary alternatives that reduce traditional 
education gaps with students' needs. It is also essential to move from education focused exclusively on science towards a comprehensive education focused on the needs of the most important actor: the patient.

Continuing medical education is meant to improve clinicians' knowledge and skills and lead to better patient care processes and outcomes. Educators are now looking to MOOC a means to improve professional medical education. This environment offers tremendous potential to improve learning outcomes beyond that provided by face-to-face medical, educational activities. Medical students and professionals have been found to prefer blended courses over traditional classroom courses, with flexible learning time and improvement in study skills being key advantages. This technology also allows students to learn at a time and place of their choosing, freeing valuable time for clinical experiences. However, most health- and medicine-related MOOCs are limited to English language countries (Robinson 2016; Setia et al., 2019). Making content available in local languages is key to a wider reach. Vadillo and Bucio (2021) indicate that MOOCs promote educational innovation, by allowing interaction between health professionals for consultation and information exchange purposes.

According to Razmerita et al. (2020) MOOC not only democratize access to education, but they also empower individuals to learn independently at their own pace. Learning in a MOOC depends on learner effort in the course, it requires students to be highly self-regulated and personally engaged (Zhu and Bonk, 2018). According to Aleman et al. (2015) the students that enrolls in a MOOC discover learning in its most open form through platforms that not only invite you to see and listen, but also to participate and collaborate. In order to achieve this, it is necessary to promote active participation, peer assessment, provide feedback and encourage participation in the discussion forums.

Academics and other stakeholders in education have utilized MOOCs not only to deliver learning experiences but also help assess student behavior and competences through their online engagement. One of the principal goals of MOOC research has been to understand better how students learn in online contexts (Barthakur et al., 2020). According to Olivares et al. (2018) the competences of the students can be classified in individual, interpersonal, and organizational impact. The first classification refers a combination of manual skills and cognitive abilities of the individual that enable their self-development; the interpersonal impact is associated with the skills for relationship and communication with others; the organizational impact is related to the management of resources to improve the results of organizations.

Despite the potential of MOOCs, the completion rate is not exceeding ten percent. There is a need for effective evaluation methods for appraising the effectiveness and success of the courses (Albelbisi et al., 2021). Evaluation methods is highly dependent on the aim of the evaluation and the size of the MOOCs. For quantitative measures, such as completion and participation rates, metrics can be easily collected through the MOOC platform. However, these metrics alone may be insufficient to provide insights into why students fail to complete the course for future improvement (Alturkistani et al., 2020). The MOOC content was designed and developed in Spanish with the participation of 15 professors from three universities in Mexico: Tecnológico de Monterrey, Universidad Nacional Autónoma de México (UNAM), and Universidad Westhill. The course has been evaluated according to six quality dimensions: pedagogical perspectives, collaboration, learning resources, time management, digital aesthetics, and functional features (Olivares et al., 2021). 
Understanding student expectations towards MOOCs has become increasingly important due to the impact of this element on the use and adoption of these type of courses (Albelbisi et al., 2021). The purpose of this study was to implement and evaluate a MOOC on educational evaluation in health sciences.

\section{Methods}

A quantitative and transactional method is used. A pilot of the MOOC was implemented during September-October 2019 to train clinical teachers from the three universities. The instruments' conceptual design is based on the classification of competences of Olivares et al. (2018). This was built by the project leaders of the three universities based on the objectives of a MOOC. The instruments of 12 items with Likert scale from 1 to 5 (where 1 totally disagrees and 5 totally agrees) were designed to measure the fulfillment of teachers' expectations according to the Expectation Confirmation Theory shown in figure 1 (Olivares et al., 2019).

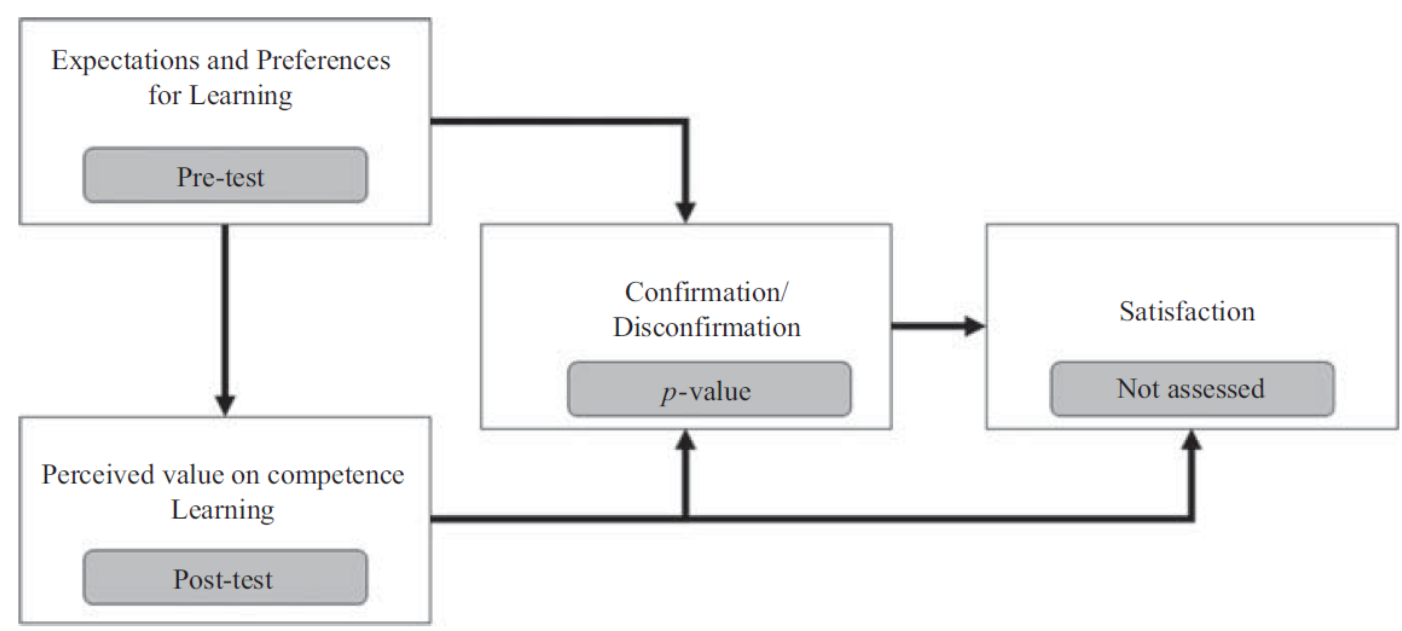

Figure 1. Expectation Confirmation Theory model (Olivares et al., 2019)

The pre-test was applied before starting the pilot course to 33 participants and the post-test at the end of the course to 29 participants. The instruments are shown in table 1, these were applied by google forms and the data was analyzed using the t-student statistical test.

Table 1. Instruments applied to participants of the pilot

\begin{tabular}{lll}
\hline Classification & Pre-test & Post-test \\
\hline Individual & $\begin{array}{l}\text { I consider that I know the subject of clinical } \\
\text { evaluation }\end{array}$ & $\begin{array}{l}\text { The course helped me increase the } \\
\text { knowledge I have about clinical evaluation }\end{array}$ \\
\hline $\begin{array}{l}\text { I compromise on delivering the activities on } \\
\text { time }\end{array}$ & \begin{tabular}{l} 
I delivered the activities on time \\
\hline $\begin{array}{l}\text { I am comfortable working with self-directed } \\
\text { learning }\end{array}$
\end{tabular} & I liked working with self-directed learning \\
\hline $\begin{array}{l}\text { I have certificates from Coursera or another } \\
\text { similar }\end{array}$ & I obtained the Coursera certificate \\
\hline & \begin{tabular}{l} 
I believe that online courses have more \\
\hline
\end{tabular}
\end{tabular}




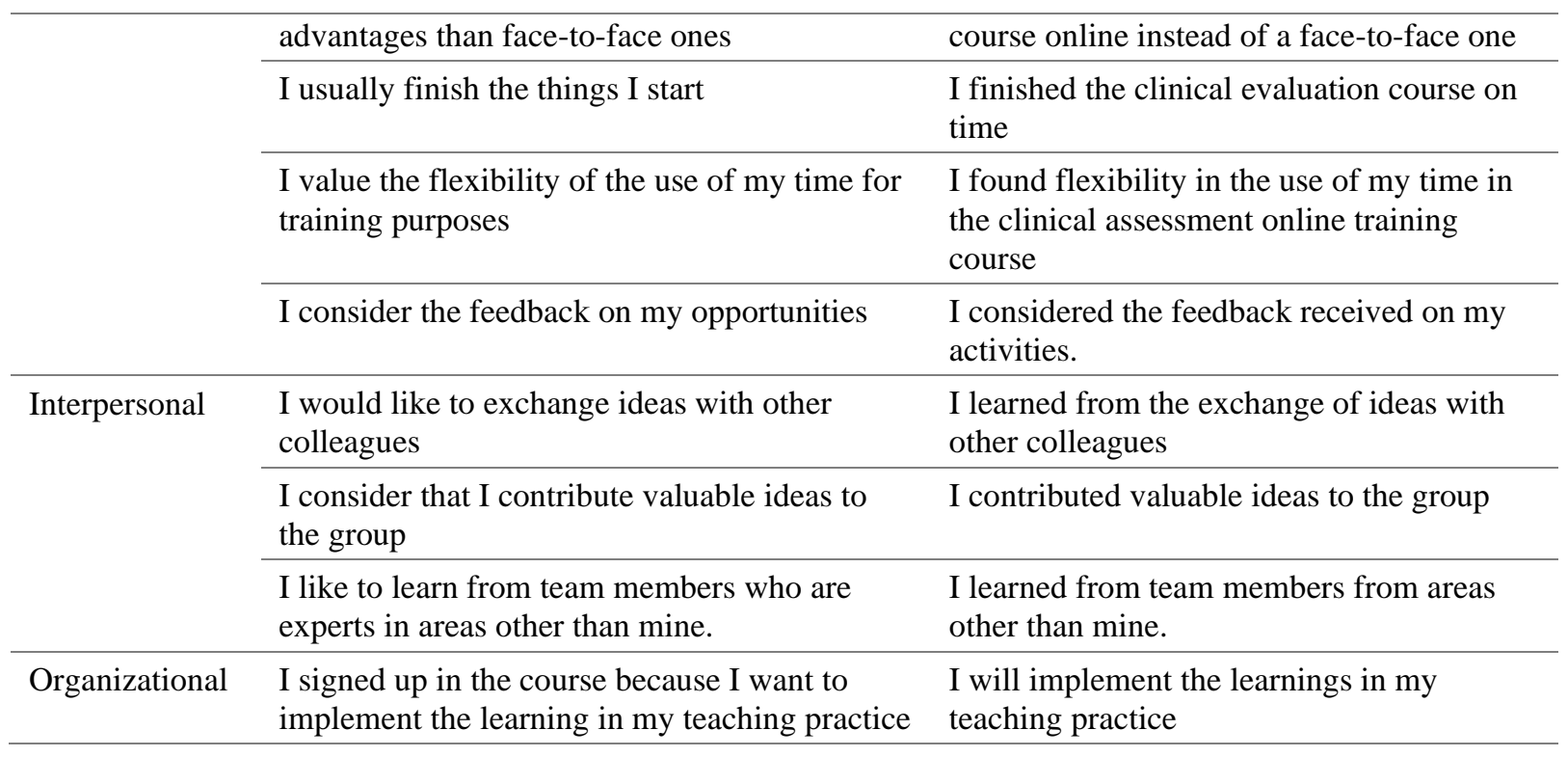

\section{Results}

The course was successfully completed by 33 clinical educators, of which 29 (12 from Tecnologico de Monterrey, 10 from UNAM, and 7 from Universidad Westhill) answered the instruments. The Cronbach Alpha in the pre-test was 0.98 and 0.88 in the post-test. According to Vogt (2017), this number indicates that questionnaires have an adequate internal consistency.

Table 2 shows the results of each question of the instruments. There is a significant difference in individual competence, as well as in the total instrument. It is observed that there is a significant difference in the individual competence, as well as in the total instrument.

Table 2. Results (* Favorable significant difference)

\begin{tabular}{|c|c|c|c|c|}
\hline Classification & Question & Pre-test mean & Post-test mean & $\mathrm{p}$-value \\
\hline \multirow{9}{*}{ Individual } & 1 & 3.75 & 4.65 & \\
\hline & 2 & 4.82 & 4.68 & \\
\hline & 3 & 4.51 & 4.65 & \\
\hline & 4 & 1.93 & 4.89 & \\
\hline & 5 & 3.34 & 4.62 & \\
\hline & 6 & 4.79 & 4.89 & \\
\hline & 7 & 4.86 & 4.27 & \\
\hline & 8 & 4.93 & 3.89 & \\
\hline & & 4.12 & 4.57 & $0.00 *$ \\
\hline \multirow[t]{4}{*}{ Interpersonal } & 9 & 4.44 & 4.17 & \\
\hline & 10 & 4.27 & 4.20 & \\
\hline & 11 & 4.89 & 4.17 & \\
\hline & & 4.54 & 4.18 & 0.00 \\
\hline Organizational & 12 & 4.86 & 4.89 & 0.30 \\
\hline Total & & 4.29 & 4.51 & $0.01 *$ \\
\hline
\end{tabular}


Figure 2 show the difference among individual, interpersonal and organizational group of items.

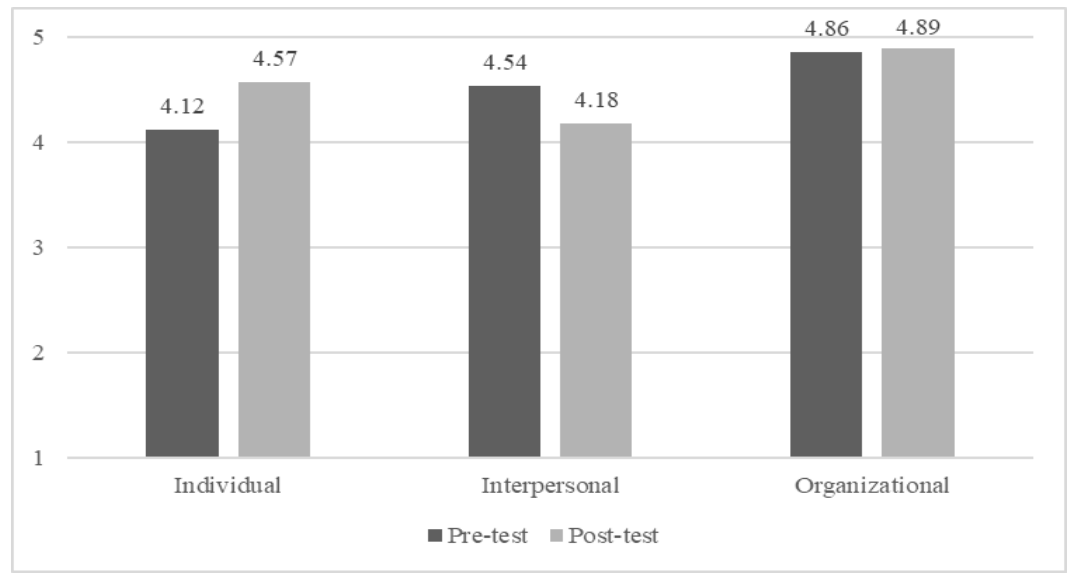

Figure 2. Results by classification

Expectations on individual performance were successfully exceeded. However, the perceived value at an interpersonal level has not met the expectations of the students. At the organizational level, expectations have been met.

\section{Discussion}

Faculty members' expectations who participated in the MOOC were exceeded in general. According to Gilfoil and Focht (2015) for the educational proposal to be considered of value, it must meet the participant's learning needs so that the effort required is based on the cost invested. Knowing the perceived value indicates how participants conceive the value of the program. In this sense, MOOCs represent opportunities for teacher training in educational evaluation.

This study also highlights the importance of learners' appreciation of MOOCs and provides feedback for designers on their strengths and weaknesses. As presented in the results, individual and organizational expectations are strong and provide a profit value before and after the course. However, the interpersonal aspects show an area of opportunity for improvement. The individual aspect indicates that the course's quality is good about expectations, and the organizational aspect points to a potential impact on the evaluation of clinical scenarios.

These opportunities suggest improving interpersonal aspects since human beings are social entities, and the learning process is strengthened by increasing the interaction of the subjects, which is why it is necessary to design social interaction activities (Razmerita et al., 2020). The MOOC assessed in the present paper shows evident strengths in the learning environment and its applicability in the clinical context but limitations regarding forming a learning community.

The MOOC for evaluation in clinical settings adds value to education quality in the health sciences formation. Assessment topics play a fundamental role in teaching and learning nowadays, including formative or summative strategies. Aligning patient caring and education in clinical settings has been a challenge for several decades Vadillo and Bucio (2021). Therefore, the presented MOOC project is considered to have a great impact at the Latin American level. 
The use of digital platforms and assessment methods for education is exponentially growing since the COVID-19 pandemic, so MOOCs become an opportunity for distance learning about topics of interest to users (Olivares et al., 2020). This has been reflected in the number of users enrolled in the course since 2019, which has increased considerably.

\section{Conclusion}

In general, the completion rate for a MOOC is low comparing participants that start the course from those that finish it. A MOOC design requires experts' feedback to validate contents, aesthetics, navigation, and other characteristics to lower the attrition rate.

It is possible to exceed the faculty expectations regarding their learning to evaluate student performance on clinical scenarios through a MOOC. Expectations on individual performance and institutional achievement were successfully exceeded. However, interpersonal aspects could be improved to develop a sustainable learning community to share interests and best practices. Since a MOOC involves self-directed learning, it is essential to create forums for discussions, peer review, and collaboration activities.

This study is limited to the results of the pilot course. The course is currently on Coursera with almost 6,000 registered users. It is intended to evaluate the satisfaction of students on a large scale, considering the completion rate, in order to make changes to promote continuous improvement.

The massive characteristic of a MOOC with relevant content and quality features may have broad implications for the quality of health science education in Latin America.

\section{Acknowledgements}

The authors would like to acknowledge the financial support of NBME National Board of Medical Examiners for this project's funding.

The authors would like to acknowledge the financial support of Writing Lab, TecLabs, Tecnologico de Monterrey, Mexico, in the production of this work.

\section{References}

Aboshady, O., Radwan, A., Eltaweel, A., Azzam, A., Aboelnaga, A., Hashem, H., Hassouna, A. (2015). Perception and use of massive open online course among medical students in a developing country: multicentre cross-sectional study. BMJ Open, 5(1).

Albelbisi, N., Al-adwan, A., Habibi, A. (2021). Impact of quality antecedents on satisfaction toward MOOC. Turkish Online Journal of Distance Education, 22(2), 164-175.

Alemán, L., Sancho-Vinuesa, T., y Gómez, M. (2015). Indicadores de calidad pedagógica para el diseño de un curso en línea masivo y abierto de actualización docente. Universities and Knowledge Society Journal, 12(1), 104-119.

Alturkistani, A., Lam, C., Foley, K., Stenfors, T., Blum, E. Van Velthoven, M., Meinert, E. (2020). Massive Open Online Course Evaluation Methods: Systematic Review. Journal of Medical Internet Research, 22(4), 1-14.

Barthakur, A., Kovanovic, V., Joksimovic, S., Siemens, G., Richey, M., Dawson, S. (2021). Assessing program-level learning strategies in MOOCs. Computers in Human Behavior 117(1), 1-13. 
Daniel, J., Vázquez, E., y Gisbert, M. (2015). The future of MOOCs: Adaptive learning or Business Model. Universities and Knowledge Society Journal, 12(1), 64-73.

Engle, D., Mankoff, C., Carbrey, J. (2015). Coursera's Introductory Human Physiology Course: Factors that Characterize Successful Completion of a MOOC. International Review of Research in Open and Distributed Learning, 16(2), 46.68.

Gilfoil, D., y Focht, J. (2015). Value-Based Delivery of Education: MOOCs as Messengers. American Journal of Business Education, 8(5), 223-237.

Razmerita, L., Kirchner, K., Hockerts, K. (2020). Modeling collaborative intentions and behavior in digital environments: the case of a massive open online course (MOOC). Academy of Management Learning and Education, 19(4), 469-502. doi.org/10.5465/amle.2018.0056.

Robinson (2016), Delivering a medical school elective with massive open online course (MOOC) technology. PeerJ, DOI 10.7717/peerj.2343.

Olivares, S., Adame, E., Avila, J., Turrubiates, M., López, M., \& Valdez, J. (2018). Valor percibido de una experiencia de inmersión educativa para el desarrollo de competencias transversales: Semana i. Educación Médica, 20(2), 93-99.

Olivares, S., Adame, E., Treviño, J., López, M., Turrubiates, M. (2019). Action learning: challenges that impact employability skills. Higher Education, Skills and Work-Based Learning, 10 (1), 203216.

Olivares, S., Esperón, R., Turrubiates, M., Nigenda, J., Sánchez-Mendiola, M. (2021). MOOC Learning Assessment in Clinical Settings: Analysis from Quality Dimensions. Medical Science Educator, https://doi.org/10.1007/s40670-020-01178-7

Setia, S., Chin, J., Chin, Y., Subramaniam, K. (2019). Massive open online courses (MOOCs) for continuing medical education - why and how? Advances in Medical Education and Practice, 10, 805812.

Vadillo, G., Bucio, J. (2018). One MOOC, many MOOCs: A multi-layered design for health-related massive courses. Investigación en Educación Médica, 7(26), 92-98. 10.22201/facmed.2007865x.2018.26.03.

Vogt W. (2007). Quantitative research methods for professionals. Boston, MA: Pearson/Allyn and Bacon.

Zhu, M., Bonk, C. (2018). Instructor Experiences Designing MOOCs in Higher Education: Pedagogical, Resource, and Logistical Considerations and Challenges. Online Learning Journal, 22(4), 203-241. 